\title{
Lealdade à marca: $O$ que é? Como medir?
}

\author{
Brand Loyalty: What is it? How to measure it?
}

Murilo Carrazedo Costa Filho'

\section{Resumo}

A lealdade à marca é um dos construtos mais estudados na literatura do marketing e de grande interesse para acadêmicos e praticantes, em função de sua estreita relação com resultados superiores para as empresas, que lhes conferem vantagens competitivas. Apesar de ser estudada empiricamente desde a década de 1950, a conceituação e operacionalização desse construto ainda hoje é um tema em discussão. Isso, por sua vez, acarreta em dificuldades conceituais de como medi-la. $O$ objetivo desse ensaio, apoiado em uma ampla revisão de literatura sobre o tema, é apresentar as diferentes concepções de lealdade e formas de medir esse construto. $O$ artigo procura também provocar reflexões acerca das diferentes formas de se medir lealdade e sugerir quando uma pode ser preferível a outras.

Palavras-chave: Lealdade à marca. Operacionalização de lealdade. Mensuração de lealdade.

\begin{abstract}
Brand loyalty is one of the most studied constructs in the marketing literature and of great interest to both marketing scholars and practitioners, due to its close link to superior results and competitive advantage to firms. Despite being empirically studied since the 1950s, the conceptualization and operationalization of this construct is still a topic under discussion. This, in turn, results in conceptual difficulties of how to measure it. The purpose of this essay, supported by an extensive literature review on the topic, is to present the different concepts of loyalty and ways to measure this construct. The article also seeks to provoke reflections on the different ways of measuring loyalty and to suggest when one may be preferable to others.
\end{abstract}

Key-words: Brand loyalty. Loyalty operationalization. Loyalty measurement.

\section{Introdução}

O fenômeno da lealdade à marca tem ocupado a atenção de acadêmicos e practitioners há mais de 60 anos, e talvez seja um dos construtos mais antigos e investigados por estudiosos do marketing. O campo de conhecimento originado dos conceitos de lealdade é, há muito tempo, uma das prioridades do MSI (Marketing Science Institute), entidade dedicada a cobrir a lacuna existente entre a teoria e a prática do marketing, por meio da realização de pesquisas que sejam de interesse da comunidade empresarial (ROCHA; PONCHIO; FRANCISCO, 2015). Tamanha dedicação aos estudos sobre lealdade deriva do reconhecimento de que a lealdade à marca está vinculada a desempenhos superiores e à conquista de vantagens competitivas, proporcionando às empresas uma alta taxa de clientes leais, menos sensíveis a preços, que permanecem com a marca por mais tempo, rejeitam as ofertas da concorrência, e proporcionam uma fonte estável de receitas (MELLENS; DEKIMPE; STEENKAMP, 1996, RAUYRUEN; MILLER, 2007; BENNETT; BOVE, 2002).

Várias pesquisas investigaram a relação entre indicadores de desempenho de empresas e o sucesso em manter uma base leal de clientes, revelando associações extremamente positivas. Por exemplo, Bender (1976) relatou que o custo de atrair novos clientes pode ser até seis vezes mais alto do que o de manter os clientes satisfeitos. Reichheld e Sasser (1990) relatam que a redução em apenas 5\% das taxas de evasão dos clientes é suficiente para aumentar os lucros das empresas em $25 \%$ a $75 \%$. Outra pesquisa identificou 
que clientes leais podem gastar mais do que clientes não leais numa razão de $5: 1$ na indústria de hotéis e 16:1 no segmento varejista (BAGOZZI; ROSA; CELBY; CORONEL,1998). Ao longo de sua vida útil de compra, um cliente leal a uma determinada organização pode valer até 10 vezes mais do que um cliente médio (ANDERSON; SRINIVASAN, 2003). A lealdade proporciona vantagens não só para as empresas, mas também aos consumidores, pois leva a um senso de segurança e previsibilidade, tornando a experiência de compras mais fácil, por meio da economia de tempo no processo de busca de informações (ROWLEY; DAWES, 2000; BENNETT; BOVE, 2002).

Apesar de um amplo consenso em relação à importância atribuída à lealdade à marca, e de uma relativa abundância de estudos sobre o tema, não se pode afirmar o mesmo no que tange à operacionalização e principalmente à medição desse importante construto (CHAUDHURI, 1995; BALDINGER; RUBINSON, 1996; MELLENS; DEKIMPE; STEENKAMP, 1996; QUESTER; LIM, 2003; AGRAWAL; GAUR; NARAYANAN, 2012; PAN; SHENG; XIE, 2012). Vieira (2012, p.229), por exemplo, destaca que "com essa ampla variedade de pontos de vista de como o fenômeno é tratado, estudos ainda necessitam ser feitos acerca de como lealdade é dimensionada e operacionalizada". Tais divergências giram em torno de quatro principais eixos, e serão abordadas com mais detalhes ao longo desse trabalho.

Em primeiro lugar, enquanto uma corrente argumenta que a manifestação da lealdade deve ser avaliada por meio de comportamento observável, outros estudiosos defendem uma abordagem baseada na atitude em relação à marca. Um segundo debate é se a lealdade deveria ser considerada em relação a uma única marca ou estendida a um conjunto de marcas. Alguns autores, por exemplo, sugerem que a lealdade a múltiplas marcas é hoje a regra, e não a exceção (BARNARD; EHRENBERG, 1997; UNCLES; WANG; KWOK, 2010). Uma terceira divergência é se a lealdade é determinada pelos atributos da marca ou fruto das características individuais do consumidor (MELLENS et al., 1996). Por fim, os estudos empíricos divergem em relação à forma de se medir a lealdade.

Vê-se, então, que por trás de um conceito aparentemente simples, escondem-se complexidades de natureza prática e conceitual que demandam reflexão e atenção por parte do pesquisador de marketing. Uma das contribuições pretendidas por este estudo é, portanto, apresentar ao leitor os principais conceitos, operacionalizações e reflexões acerca da forma de medir o construto lealdade à marca, por meio de uma extensa revisão de literatura. No Brasil, embora o interesse sobre o tema venha crescendo nas últimas duas décadas (ROCHA; PONCHIO; FRANCISCO, 2015; VISENTINI; FENNER, 2017), pouco se tem debatido acerca das dificuldades e cuidados que se deve tomar ao definir e medir o construto lealdade à marca. Esta é uma das lacunas que este ensaio procura preencher.

Diante do que foi exposto anteriormente, esse ensaio tem os seguintes objetivos: (1) apresentar uma descrição e exposição - apoiada em uma ampla revisão de literatura sobre o tema - acerca das diferentes abordagens de lealdade, tanto no que tange à sua conceituação quanto à sua mensuração. (2) Provocar reflexões acerca das diferentes formas de se medir lealdade e sugerir quando uma pode ser preferível a outras.

Esse artigo está estruturado em seis seções, incluindo esta introdução. A seção 2 apresenta o método utilizado nesse trabalho. Na seção 3, apresenta-se um histórico evolutivo sobre o conceito, e os trabalhos e autores seminais que se envolveram com o tema da lealdade à marca. A seção 4 apresenta um breve resumo da definição de lealdade segundo alguns dos principais estudiosos sobre o tema. Nesta parte, expõe-se também o debate acerca das diferentes abordagens conceituais sobre lealdade. Essas diferentes abordagens impactam diretamente as formas de se medir lealdade, que são discutidas na seção 5 . Por fim, a seção 6 apresenta as conclusões e sugestões de estudos futuros.

\section{Método}

O presente artigo é de natureza essencialmente teórica. Trata-se, portanto, de uma pesquisa exploratória, utilizando análise de dados secundários, obtidos após extenso levantamento em bases de dados acadêmicas. Diferente de estudos bibliométricos - em que se procura mensurar quantitativamente a produção científica sobre um tema a partir de uma coleção de artigos selecionados em um período delimitado (SPLITTER; 
ROSA; BORBA, 2012) - e também de meta-análises, nas quais se procura obter um valor que represente a força da associação entre uma ou mais variáveis a partir de estudos anteriores (BREI; VIEIRA; MATOS, 2014), o processo de busca da literatura para este ensaio se deu de forma menos rígida e sistemática.

Uma primeira busca foi feita nos periódicos internacionais das bases disponíveis na biblioteca eletrônica da PUC-Rio, utilizando-se as palavras-chave "brand loyalty", "marketing", e "consumer" no campo "título da publicação" para o período 2000-2019. O mesmo procedimento foi realizado para a busca de publicações nacionais na base Spell, com a as palavras-chave em língua portuguesa.

Essa primeira busca resultou em 330 artigos, dos quais cerca de 50 artigos foram filtrados a partir da leitura dos abstracts, com base na sua relevância para os temas a serem tratados (conceituação, operacionalização e mensuração). Por meio desses artigos, a literatura seminal sobre lealdade (por exemplo, BROWN, 1952; DAY, 1969; DICK; BASU, 1984; OLIVER; 1999) e outros estudos chave foram incorporados.

\section{Origens dos Estudos Sobre Lealdade}

Dada a sua relevância, não é de se surpreender que o conceito de lealdade tenha sido um dos principais temas de estudo entre acadêmicos há muito tempo. Copeland (1923) talvez tenha sido o primeiro a avaliar a lealdade quando propôs uma classificação de consumidores, dividindo suas atitudes em relação às marcas em estágios crescentes de engajamento: reconhecimento, preferência e insistência. Embora o autor não tenha utilizado o termo lealdade, sua classificação de atitude de insistência é análoga à de lealdade. Apesar da crescente preocupação sobre o fenômeno de lealdade desde então, foi apenas nos anos 1950 que o conceito começou a ser estudado empiricamente.

Para muitos, o primeiro a estudar empírica e sistematicamente o fenômeno de lealdade foi Brown (1952). Em uma série de artigos na revista Advertising Age, ele demonstrou que as famílias tinham a tendência de concentrar suas compras em alguns conjuntos de marcas de forma mais sistemática. Utilizando dados de um painel de consumidores, o autor analisou a sequência de compras de vários produtos por um período de um ano, e propôs uma classificação de consumo de marcas das famílias quanto ao padrão de repetição de compras em: (a) lealdade não dividida ou consistente, (b) lealdade dividida, (c) lealdade instável e (d) não lealdade. Considerando-se, por exemplo, uma sequência de compras de duas marcas A e B, Brown (1952) distinguiu lealdade consistente, representada por uma sequência AAAAAA, de lealdade dividida, como na sequência $A B A B A B$, e lealdade instável, como numa sequência $A A A B B B$.

A despeito de sua contribuição, o trabalho de Brown (1952) foi criticado por não apresentar regras de classificação formais. Esse problema foi contornado por Cunningham (1956), que utilizou o mesmo quadro referencial, mas apresentou medidas mais precisas do construto. O trabalho de Cunningham (1956) trouxe outros avanços, como o conceito de lealdade a múltiplas marcas, correlações de lealdade e características do consumidor. Mais tarde, Tucker (1964) inovou ao utilizar uma metodologia baseada em experimentos, utilizando o valor monetário necessário a induzir o consumidor a trocar de marca como uma medida de lealdade.

O problema com as pesquisas que até então vinham sendo publicadas sobre o fenômeno de lealdade era que o construto era basicamente considerado como o resultado de comportamentos observados. Surge então uma escola de autores que procuram definir a lealdade como um fenômeno baseado nas atitudes do consumidor. Esses autores criticavam a definição de lealdade como um fenômeno puramente comportamental, baseando-se no fato de que o comportamento de repetição de compra não é necessariamente representativo de lealdade, uma vez que um consumidor pode comprar um produto repetidamente por outras razões que não lealdade, como, por exemplo, preços mais baixos. Day (1969) é considerado por muitos como o primeiro a assumir que a lealdade à marca é um fenômeno que precisa levar em conta os aspectos atitudinais, envolvendo elementos afetivos e cognitivos de percepção do consumidor em relação a uma determinada marca (AMINE, 1998; HOMBURG; GIERING, 2001; KABIRAJ; SHANMUGAN, 2011). A partir daí, muitos estudos passaram a incorporar a atitude na operacionalização de lealdade. 


\section{Conceito de Lealdade}

Conforme mencionado anteriormente, o conceito de lealdade foi durante muito tempo relacionado ao comportamento de compra repetida de uma mesma marca em um determinado período de tempo. Tucker (1964), por exemplo, definia lealdade em termos puramente comportamentais:

O grau de lealdade do consumidor à marca pode ser determinado em termos da frequência relativa com que ele escolhe uma marca preferivelmente a outra. [...] Nenhuma consideração deve ser dada ao que o indivíduo pensa ou o que se passa no seu sistema nervoso central. Seu comportamento é a declaração completa do que é lealdade à marca (TUCKER, 1964, p. 32. Grifo do autor).

A lógica subjacente a esta abordagem é o condicionamento instrumental, no qual se assume que o comportamento consistente de recompra já reflete a existência de reforço positivo e forte ligação do tipo estímulo-resposta. Para os adeptos a esta abordagem, a compra leva a uma recompensa que induz à recompra da marca (por exemplo, bom desempenho), ou a uma punição que induz o consumidor a trocar de marca (por exemplo, crítica de amigos e familiares). Nesta abordagem, a lealdade à marca é considerada uma consequência do comportamento, ao invés de uma explicação para esse comportamento (BALLESTER, 2004).

Porém, para os teóricos cognitivistas, esta abordagem não questiona a intencionalidade do comportamento, pois desconsidera os aspectos cognitivos e afetivos envolvidos no processo de compra. Tais aspectos, segundo esses críticos, são de extrema importância para distinguir a lealdade verdadeira da lealdade espúria, na qual a sequência ou proporção de compras de uma mesma marca poderia estar associada a fatores contextuais, tais como preços baixos, melhor exposição do produto, ou simplesmente a ausência de outras opções no momento da compra, não representando, portanto, lealdade verdadeira (DAY, 1969; DICK; BASU, 1994; BENNET; RUNDLE-THIELE, 2002).

Em linha com essa perspectiva, Peter e Olson (2009, p.396) definem lealdade como "o comprometimento intrínseco de comprar repetidamente uma marca em particular. Ela é diferente do comportamento de compra repetido porque este último se concentra apenas na ação comportamental, sem considerar os motivos dessa relação habitual". Já Oliver (1999) apresentou uma definição envolvendo três componentes: cognição, afeto e intenção comportamental. Ele define lealdade como:

Um comprometimento profundo em recomprar ou adotar um produto ou serviço consistentemente no futuro, a despeito de influências situacionais e esforços de marketing que possam ter o potencial de causar um comportamento de troca de marca. (OLIVER, 1999, p. 34).

A definição de lealdade considerada por muitos como sendo a mais abrangente e a mais adotada (BLOEMER; KASPER, 1995; RUNDLE-THIELE; BENNETT, 2001; KNOX; WALKER, 2003; BALLESTER, 2004) é a de Jacoby e Kyner (1973), baseada em seis condições necessárias e coletivamente suficientes para o desenvolvimento de lealdade. Para esses autores, a lealdade é:

(1) uma resposta com viés (não aleatória), (2) comportamental, (3) expressa ao longo do tempo, (4) por uma unidade de tomada de decisão, (5) com respeito a uma ou mais alternativas de marcas em um grupo dessas marcas, e (6) é uma função de processos psicológicos (tomada de decisão, avaliação). (JACOBY; KYNER, 1973, p.2).

Esta definição é destacada e adotada por muitos autores como a mais completa, pois ela cobre todos os aspectos deste construto multifacetado (MELLENS et al., 1996; KNOX; WALKER, 2003). A lealdade é uma resposta comportamental porque envolve compras reais de uma marca. É também uma resposta comportamental com viés, o que implica que ela não é aleatória, ou seja, deve haver uma tendência sistemática no padrão de compras de uma marca. Assim, a escolha de uma marca não é independente das compras passadas de um consumidor. A probabilidade de compra de uma marca em uma ocasião de compra depende, portanto, das compras anteriores. Ela também é uma resposta comportamental porque envolve compras reais de uma marca. Afirmações de preferências de marcas não são suficientes para assegurar lealdade à marca. É preciso que a lealdade seja expressa sobre um horizonte de tempo, porque um viés incidental a favor de uma marca não garante lealdade. É preciso haver certa consistência do padrão de compra ao 
longo de certo período de tempo para que a lealdade seja caracterizada. Para definir lealdade, é preciso identificar a unidade de tomada de decisão, que pode ser um indivíduo, um domicílio ou uma empresa. Outra condição é que uma ou mais marcas sejam selecionadas a partir de um conjunto de marcas. Isto implica que os consumidores podem ser na verdade leais a mais de uma marca, especialmente em bens de baixo envolvimento. Esta condição para lealdade também implica que o consumidor deve ter a oportunidade de escolher dentre um conjunto de alternativas. Ou seja, "antes de se falar em lealdade à marca, deve-se ter a oportunidade de ser desleal" (JACOBY; CHESTNUT, 1978, p.82). Por último, a lealdade é uma função de processos psicológicos. Isto implica em um comprometimento - portanto uma atitude - do consumidor para com a marca, que segundo Jacoby e Chestnut (1978), é um elemento essencial para a lealdade.

\subsection{Abordagens Comportamentais e Atitudinais}

A seção anterior descreve como as abordagens do conceito de lealdade passaram de uma visão predominantemente comportamental para um construto complexo e multifacetado, que envolve tanto o comportamento de repetição de compra quanto atitudes favoráveis em relação ao objeto de lealdade (DICK; BASU, 1994; HA, 1998; BENNETT; BOVE, 2002), e sobre as diferenças destas abordagens nos debruçaremos com maior profundidade nesta seção.

A abordagem comportamental pressupõe que a lealdade é definida por um comportamento de repetição de compra. Comportamentos são "ações manifestas que podem ser diretamente observáveis e avaliadas por outras pessoas" (PETER; OLSON, 2009, p. 531). A lealdade comportamental é baseada no histórico de compras do consumidor e, apesar de alguns autores não negarem a presença de processos internos, parte da premissa que, pelo fato de estes não poderem ser medidos diretamente, não assumem relevância na pesquisa (BASS, 1974; DELGADO, 2004). Esta perspectiva caracteriza-se por dar pouca ênfase aos processos de pensamento e formação das atitudes subjacentes ao comportamento do indivíduo. Destarte, para os adeptos desta abordagem, o comportamento é a manifestação completa do que é a lealdade à marca (BALLESTER, 2004).

Bennett e Bove (2002) afirmam haver duas perspectivas dentro da abordagem comportamental: a de reforço e estocástica. A visão de reforço sustenta que o comportamento é modificado através de reforçadores externos (ROTHSCHILD; GAIDIS, 1981). Em um contexto de marketing, esses reforços podem estar na forma de promoções de vendas, preços baixos, etc. A abordagem estocástica, ou probabilística, sugere que a medição da lealdade é baseada no histórico de compras do cliente, em que nenhum elemento cognitivo explica os motivos de compra subjacentes em geral e as ações futuras em particular (ZINS, 2001), que tem pouco a ver com envolvimento ou processamento de atitudes (BASS, 1974, OLSHAVSKY; GRANBOIS, 1979).

A atratividade da abordagem comportamental deriva de sua relativa facilidade de mensuração, que se baseia na observação de compras reais ao longo de um determinado período (MELLENS et al., 1996). Contudo, concentrar-se em apenas aspectos comportamentais de lealdade pode fornecer avaliações superestimadas da lealdade verdadeira, já que a lealdade comportamental pode ser influenciada por vários outros fatores, como, por exemplo, a disponibilidade do produto (ZINS, 2001).

Já na abordagem atitudinal, a lealdade é concebida em termos de atitudes e sentimentos positivos, em que se manifestam elementos de envolvimento emocional com a marca. A atitude é uma avaliação geral de um conceito por uma pessoa e reflete sentimentos de favorecimento ou preferência em relação a objetos que "podem ser formadas por um processo cognitivo que requer uma integração relativamente controlada e consciente de informações sobre o objeto, ou por uma reação do sistema afetivo com grande medida automática e inconsciente" (PETER; OLSON, 2009, p. 530). Ao contrário da abordagem comportamental, que defende a natureza estocástica da lealdade, ancorada pela observação direta e por um paradigma indutivo, a abordagem atitudinal busca explicações teóricas e determinísticas para a formação da lealdade, ancorada por um paradigma hipotético-dedutivo (BALLESTER, 2004).

Ao passo que na abordagem comportamental o grau de lealdade à marca do consumidor é inferido a partir de seu comportamento de compra observado, a abordagem atitudinal concentra-se nos processos avaliativos e cognitivos subjacentes ao interpretar uma determinada decisão de compra como evidência de lealdade à marca (DEKIMPE et al., 1997). Os seguidores desta abordagem defendem que o comportamento 
de repetição de compra nem sempre garante a lealdade do consumidor, pois fatores situacionais como preço, ofertas, disponibilidade, etc. podem influenciar a repetição de compra sem que o consumidor tenha necessariamente um vínculo afetivo com a marca.

\subsection{Abordagem Composta}

Muitos autores (por exemplo, DAY, 1969; DICK; BASU, 1994; RAUYRUEN; MILLER, 2007) argumentam que as abordagens comportamental e atitudinal, isoladamente, não descrevem o fenômeno da lealdade completamente, e que uma perspectiva composta, considerando ambas as abordagens, seria mais apropriada. Sob esta perspectiva, Day $(1969$, p.30) afirma que "lealdade implica em compras repetidas baseadas em fatores cognitivos, afetivos, avaliativos e disposicionais - os componentes clássicos de atitude". A perspectiva composta de lealdade promove uma reconciliação das duas correntes de pensamento, ao combinar medidas de atitude e comportamento na conceituação de lealdade. Além de combinar essas duas dimensões, a perspectiva composta permite classificar e distinguir diferentes tipos de lealdade. Além de Day (1969) e Jacoby (JACOBY; KYNER, 1973; JACOBY; CHESTNUT, 1978), autores seminais que alertaram para as deficiências de conceituação e mensuração de lealdade puramente comportamental, os autores que aparentemente mais influenciaram a adoção da abordagem composta foram Dick e Basu (1994) e Oliver (1999), cujos artigos encontram-se entre os três mais citados na literatura sobre lealdade (ROCHA; PONCHIO; FRANCISCO, 2015).

Dick e Basu (1994) unificaram as duas perspectivas estabelecendo um modelo de lealdade baseado nas duas abordagens. Segundo os autores, o status de lealdade pode ser avaliado em termos da força da relação entre a atitude relativa à marca e o comportamento de repetição de compra, gerando uma matriz de atitude relativa vs. comportamento, que resulta em quatro tipos de lealdade, como ilustrado na Figura 1: lealdade real, lealdade latente, lealdade espúria e sem lealdade. $\mathrm{Na}$ lealdade real, a atitude em relação à marca é positiva e o padrão de repetição de compra é alto. Já na lealdade espúria, ocorre um processo inercial de repetição com pouca ou nenhuma atitude em relação à marca.

Figura 1: Tipologia de lealdade de Dick e Basu

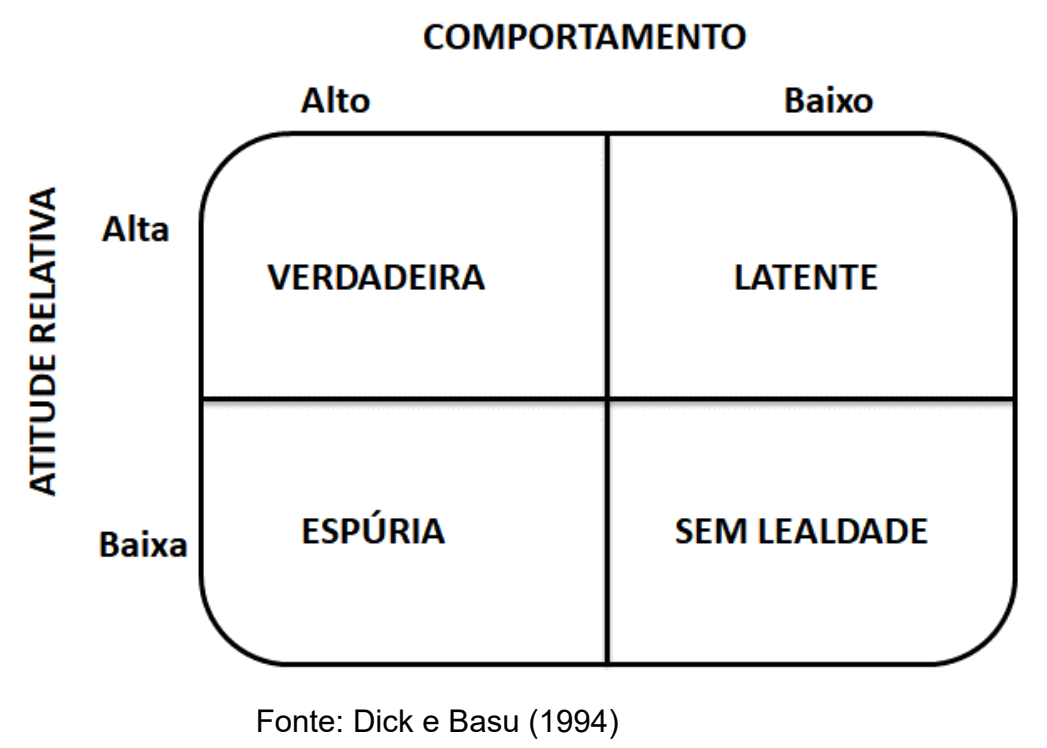

A lealdade espúria, às vezes chamada de inércia, ocorre quando há um nível baixo de afeto acoplado a um padrão alto de repetição de compra, em que fatores não atitudinais, tais como conveniência, preços, promoções, barreiras de troca, ou a falta de uma percepção de diferenciação dos produtos influenciam o comportamento de compra, mesmo que a atitude em relação à marca não seja positiva e não haja um envolvimento do consumidor com a marca. Por outro lado, uma atitude altamente favorável a uma marca, porém sem um comportamento de compra repetida observável é característico de lealdade latente. Este cenário é mais provável quando fatores externos limitam ou impedem que o consumidor adote sua marca 
preferida, como por exemplo, preços muito altos ou a indisponibilidade da marca no ponto de venda. A lealdade verdadeira só é obtida quando ocorre um alto grau de ligação com a marca aliado a um padrão de repetição de compra.

Embora muitos autores defendam a superioridade de uma abordagem composta atitude-comportamento (por exemplo, PRITCHARD; HOWARD; HAVITZ, 1992; DICK; BASU, 1994; OLIVER, 1999; CHAUDHURI; HOLBROOK, 2001; HOMBURG; GIERING, 2001), ainda hoje a academia parece se dividir. Recentes revisões de literatura e meta-análises sobre o tema indicam haver um equilíbrio entre estas abordagens na operacionalização de lealdade nos estudos empíricos sobre o fenômeno (YOO; BAI, 2013; CENGIZ; AKDEMIR-CENGIZ, 2016; VISENTINI; FENNER, 2017). Por exemplo, Yoo e Bai (2013) conduziram uma revisão de pesquisas sobre lealdade nos principais periódicos internacionais de turismo e negócios entre 2000 e 2010 e identificaram que, embora a abordagem atitudinal predominasse em $41 \%$ dos estudos, $21 \%$ deles utilizaram medidas puramente comportamentais, ao passo que $38 \%$ utilizaram medidas compostas. Já em outra revisão da literatura internacional sobre lealdade à marca, envolvendo estudos entre 2001 a 2015, Cengiz e Akdemir-Cengiz (2016) relatam haver um predomínio de medidas compostas (40\%), e igualdade entre estudos que utilizam medidas comportamentais e atitudinais (30\% em cada caso), padrão similar também em estudos brasileiros, como relatam Visentini e Fenner (2017) em bibliometria de estudos sobre o tema publicados em periódicos nacionais e anais do EMA e Enanpad entre 2010 e 2016.

Tendo em vista o exposto acima, o que seria então mais apropriado para se medir a lealdade do consumidor a uma marca? Por um lado, a simples observação de compras repetidas pode não refletir adequadamente a lealdade do consumidor, e pode colocar uma empresa em uma perigosa zona de conforto, em que situações contextuais (preço, por exemplo) mascaram a verdadeira lealdade. Nesse caso, uma mudança de fatores situacionais pode alterar o padrão de compras do consumidor, fazendo com que este mude de marca, deixando a empresa em uma posição de desvantagem. Por outro lado, medidas baseadas em atitude e intenção de compra podem também sofrer vieses de respostas ou refletir apenas estados desejáveis do consumidor, que podem não se concretizar, também por questões situacionais (custos de mudança, por exemplo). Nesse sentido, a abordagem composta parece ser mais recomendável, pois captura os dois aspectos da lealdade.

Contudo, o mais importante é adequar a abordagem utilizada aos objetivos de pesquisa e aos recursos disponíveis. Por exemplo, em recente pesquisa, Sheth e Koschmann (2019) utilizaram dados de um painel de compras de 62.000 consumidores americanos para avaliar as flutuações de participação de mercado das marcas de refrigerantes Coca-Cola e Pepsi. A operacionalização de lealdade em bases puramente comportamentais foi adequada, além de ser a única disponível (os autores não tinham medidas de atitudes disponíveis) para os objetivos de pesquisa dos autores: demonstrar que a lealdade à marca é estável ao longo do tempo em mercados maduros como o de refrigerantes, e que as empresas não se engajam em guerras de preço de forma agressiva, como, segundo os autores, se pressupunha.

Em contrapartida, Coutinho, Mesquita e Muylder (2018) utilizaram medidas puramente atitudinais para mensurar o que chamam de lealdade suprema (ultimate loyalty) junto a donos de motocicletas Harley-Davidson. O objetivo neste estudo era entender os antecedentes que levam os indivíduos a uma relação estreita e apaixonada com uma marca específica. O enfoque da pesquisa era, portanto, nos elementos cognitivos e afetivos subjacentes a um processo de engajamento com a marca. Neste caso, era desnecessária qualquer medida comportamental, até porque o delineamento do estudo partiu da premissa de que os participantes são efetivamente leais à marca Harley-Davidson.

Por outro lado, se o objetivo é entender como um determinado segmento é caracterizado em termos de lealdade, e mapeá-lo para o desenvolvimento de estratégias de marketing e tomadas de decisão, é imprescindível que se operacionalize a lealdade de forma composta. Neste caso, uma matriz como a de Dick e Basu (1994) é muito reveladora. Um bom exemplo é a segmentação proposta por Worthington, RusselBennett e Härtel (2010), que resultou em um modelo tridimensional de categorização de consumidores baseado em comportamentos e dois tipos de atitudes: lealdade emocional e lealdade cognitiva (Figura 2). 
Figura 2: Tipologia de Worthington, Russel-Bennett e Härtel

\begin{tabular}{|c|c|c|c|c|}
\hline & \multicolumn{2}{|c|}{ Alta Lealdade Emocional } & \multicolumn{2}{|c|}{ Baixa Lealdade Emocional } \\
\hline & Alta Lealdade Cognitiva & Baixa Lealdade Cognitiva & Alta Lealdade Cognitiva & Baixa Lealdade Cognitiva \\
\hline $\begin{array}{l}\text { Alta Lealdade } \\
\text { Comportmental }\end{array}$ & Leais Estáveis & Apaixonados & Leais Funcionais & Vulneráveis \\
\hline $\begin{array}{l}\text { Baixa lealdade } \\
\text { comportamental }\end{array}$ & Potenciais "Quentes" & Esperançosos & Potenciais "Frios" & Não Leais \\
\hline
\end{tabular}

Fonte: Worthington, Russel-Bennett e Härtel (2010)

No framework acima, proposto para uma empresa do mercado de cartões de crédito, os clientes dos segmentos "vulneráveis", "potenciais quentes", "potenciais frios" e "esperançosos" deveriam ser priorizados, segundo os autores, para alocação de recursos e estratégias de captação ou aumento de negócios. Os autores atentam que o mais importante é que, para cada segmento, uma estratégia diferente deve ser adotada. Os "potenciais quentes" e "esperançosos", por exemplo, representariam um potencial de crescimento alto, pois são altamente envolvidos afetivamente com a marca, mas não utilizam o cartão de crédito da empresa com frequência. Para o primeiro grupo, uma campanha que dobrasse o número de pontos no programa de fidelidade poderia mudar o comportamento e estimular maior uso do cartão da empresa. Já para os "esperançosos", que têm alto envolvimento afetivo com a marca, mas baixa lealdade cognitiva, uma campanha de lembrança de marca e do programa de fidelidade, com um convite para uma pré-estréia ou uma noite especial de compras, onde o uso do cartão é recompensado, também pode reativar o uso do cartão.

\subsection{Lealdade Multi-Marcas}

Outra questão que gera debate entre os pesquisadores é se a lealdade deve ser definida em termos de uma única marca ou de um conjunto de marcas. Os consumidores podem ter preferência por marcas diferentes de uma mesma categoria de produtos ou serviços. Isso pode ser mais fácil de ocorrer para produtos com baixo envolvimento (MELLENS et al., 1996). Sheth (1970, p.348) argumenta que "obviamente, um consumidor é leal não apenas a uma, mas a muitas marcas no mercado, embora possa apresentar mais lealdade a uma marca sobre outras". Alguns autores, inclusive, sugerem que a lealdade a múltiplas marcas é hoje a regra, e não a exceção (BARNARD; EHRENBERG, 1997; UNCLES; WANG; KWOK, 2010).

Mellens et al. (1996) afirmam que o consumidor muitas vezes não avalia marcas em uma escala contínua, mas os classifica entre aceitáveis e não aceitáveis. Um padrão inconsistente de compras poderia mascarar facilmente um comportamento de lealdade, caso o consumidor seja leal a múltiplas marcas. Nestes casos, o consumidor pode ser indiferente a uma ou outra opção, mas exibir lealdade a um conjunto de marcas e não a apenas uma única alternativa.

Similar ao debate sobre a medição comportamental vs. atitudinal, medir a lealdade a uma única marca ou sobre múltiplas marcas envolve também trade-offs e certas dificuldades. A principal delas talvez seja determinar o que constitui uma lealdade a múltiplas marcas. Uma compra alternada de duas marcas certamente caracterizaria lealdade, mas a partir daí como resolver a questão? Uma saída seria determinar um valor de corte para o share da marca em um conjunto de compras repetidas, acima do qual o consumidor é considerado leal. Ainda assim, o estabelecimento deste ponto de corte é sujeito à subjetividade.

Outra alternativa para esse dilema seria utilizar o tamanho e composição do conjunto de consideração dos consumidores, que pode ser definido como um conjunto mais restrito de marcas que os consumidores elegem para reduzir o universo de opções a um número cognitivamente mais gerenciável (NEDUNGADI, 1990; VAN NIEROP et al., 2010; HAUSER et al. , 2010). Um conjunto de consideração grande e diverso, por exemplo, é provavelmente um indicativo de falta de lealdade a qualquer marca. Empiricamente, os conjuntos de consideração apresentam correlações estreitas com a lealdade à marca (OSTLUND, 1973; REILLY; PARKINSON, 1985; TERECH; BUCKLIN; MORRISON, 2009). 


\section{Mensuração de Lealdade}

A mensuração de lealdade está longe de ser um processo simples, e envolve a necessidade de se conceituar e operacionalizar o construto de forma precisa. Uma discussão muito rica sobre o debate acerca da mensuração de lealdade é promovida por Mellens et al. (1996). Os autores classificam as medidas de lealdade em quatro grupos, baseadas nas seguintes dimensões dicotômicas: (1) medidas atitudinais vs. comportamentais, (2) medidas orientadas por marcas vs. orientadas por indivíduos.

\subsection{Medidas atitudinais vs. comportamentais}

Como já discutido, as medidas operacionais de lealdade dividem-se em comportamentais ou atitudinais dependendo da ênfase que se dá ao ato da compra ou aos componentes cognitivo e afetivo, respectivamente. Ambas apresentam vantagens e desvantagens.

As medidas comportamentais se baseiam nos registros e/ou observações das compras reais dos consumidores realizadas ao longo de um período de tempo estabelecido. A principal vantagem dessas medidas é que elas podem ser diretamente vinculadas ao desempenho das empresas, e, portanto, são atraentes aos olhos dos seus executivos. Outra vantagem, segundo Mellens et al. (1996), é que a sua medição é relativamente fácil de ser executada. A principal limitação das medidas baseadas em comportamento reside na dificuldade em se diferenciar a lealdade verdadeira de lealdade espúria. Outra limitação é que, embora os dados coletados por medidas comportamentais representem com precisão o comportamento passado, eles não são necessariamente uma boa representação de comportamento futuro, especialmente quando as circunstâncias mudam (DAY; SHOCKER; SRIVASTAVA, 1979). Os dados de compras sozinhos também não permitem identificar se o indivíduo é de fato o decisor da compra, já que ele pode estar comprando para outras pessoas. Isso pode gerar ainda mais imprecisão se, em uma sequência de compras, ele adquirir produtos ora para si mesmo, ora para terceiros.

Por outro lado, as medidas baseadas em atitude são fundamentadas em declarações de preferências, comprometimento, intenções de compra, etc., que enfatizam os elementos cognitivo e afetivo da lealdade à marca. Elas têm a vantagem de permitir o discernimento entre a lealdade e compra repetida, e como são obtidas por meio de surveys, permitem que se assegure que os dados coletados sejam do tomador de decisão. Contudo, a principal limitação dessas medidas está na imprecisão de que as atitudes do consumidor se traduzam em comportamentos reais de compra. Por exemplo, um consumidor pode demonstrar uma atitude favorável a uma marca, mas não a adquirir na ocasião de compra porque julgou que o preço estava muito alto. Outra desvantagem é que as medidas atitudinais podem ser incidentais, pois são coletadas em um determinado instante. Pesquisas longitudinais podem mitigar esse problema, mas podem se tornar caras e de difícil execução.

Como já citado anteriormente, a adoção de medidas compostas pode contornar os problemas descritos anteriormente. Porém, isso introduz maior complexidade na medição do construto, aumentando o número de escalas necessárias, ou introduzindo dificuldades ao se unir em uma única medida construtos conceitualmente distintos. Outra ideia para mitigar o problema seria a introdução de fatores situacionais na medição (por exemplo, condições de preço e disponibilidade). Neste caso, contudo, aumenta-se ainda mais a complexidade do delineamento de pesquisa, e isso é um trade-off que o pesquisador terá que gerenciar.

É importante destacar também dois cuidados que se devem ter ao medir a lealdade de forma composta. Em primeiro lugar, a lealdade comportamental e a lealdade atitudinal são conceitualmente distintas, e o pesquisador deve respeitar e tratar os dois construtos como construções separadas em análises posteriores, como, por exemplo, em modelagem de equações estruturais. Não se deve confundir abordagem composta de lealdade com medida composta de lealdade, efetuando-se o colapso de medidas comportamentais e atitudinais em uma escala somada (summated scale). Isto é equivocado, e fere conceitualmente a dimensionalidade distinta destes dois construtos (PRITCHARD; HOWARD; HAVITZ, 1992; BENNETT; BOVE, 2002).

Um segundo ponto importante é em relação ao que é de fato comportamental e atitudinal. As medidas comportamentais são baseadas em ações observáveis, obtidas, por exemplo, por dados coletados por painéis, ou medidas de lembrança de compras passadas coletados por instrumentos de surveys. As atitudes, por 
sua vez, são medidas por gostos e preferências declaradas pelos consumidores. Nesta categoria, encontrase um tipo especial de atitude que é a intenção de compra, que equivale à fase conativa do processo de formação de lealdade (OLIVER, 1999), e não deve ser confundida com medida comportamental, que corresponderia à fase de ação do modelo de Oliver (1999). Nesta categoria também se encontram medidas frequentemente usadas como proxies para lealdade atitudinal, como a recomendação boca a boca. Este equívoco é cometido até mesmo por pesquisadores experientes do marketing em estudos de lealdade, como por exemplo, Chaudhuri e Holbrook (2001), que operacionalizaram lealdade de compra (ou seja, comportamental) como "eu comprarei esta marca na próxima vez que comprar [produto X]" e "eu pretendo continuar comprando esta marca", duas escalas que refletem intenções e não exatamente comportamentos de compra (CENGIZ; AKDEMIR-CENGIZ, 2016).

\subsection{Medidas orientadas por marcas vs. orientadas por indivíduos}

As diferenças dessas duas abordagens baseiam-se em perspectivas distintas de que a lealdade à marca pode ser originada da avaliação do consumidor quanto aos atributos da marca ou considerada como fruto das características individuais do consumidor.

Quando medidas orientadas por marca são utilizadas, um valor de lealdade é estimado para a marca, e as diferenças em lealdade entre os indivíduos tornam-se menos relevantes, sendo mais usual a agregação dos dados coletados (MELLENS et al., 1996). Essas medidas são mais apropriadas quando se deseja comparar o nível de lealdade a uma alternativa entre um conjunto de marcas, que é provavelmente mais interessante quando as empresas buscam formular suas estratégias de marketing em um cenário competitivo. É preciso tomar cuidado, no entanto, quando a população estudada for muito heterogênea, já que em geral trabalha-se com dados agregados.

As medidas orientadas por indivíduos são utilizadas quando o interesse é avaliar o nível de lealdade do indivíduo, e torna-se menos importante a que marca específica o indivíduo é leal. É possível segmentar ainda mais essas medidas entre aquelas que medem a lealdade do consumidor dentro de uma determinada categoria de produtos, e aquelas que medem a lealdade em função de características intrínsecas do consumidor, como traços de personalidade, por exemplo. Essas medidas são mais apropriadas para segmentar a população de acordo com características do consumidor.

Com base nessas quatro dimensões, Mellens et al. (1996) desenvolveram um framework de categorias de medição de lealdade, conforme apresentado na Figura 3:

Figura 3: Matriz de medição de lealdade de Mellens et al.

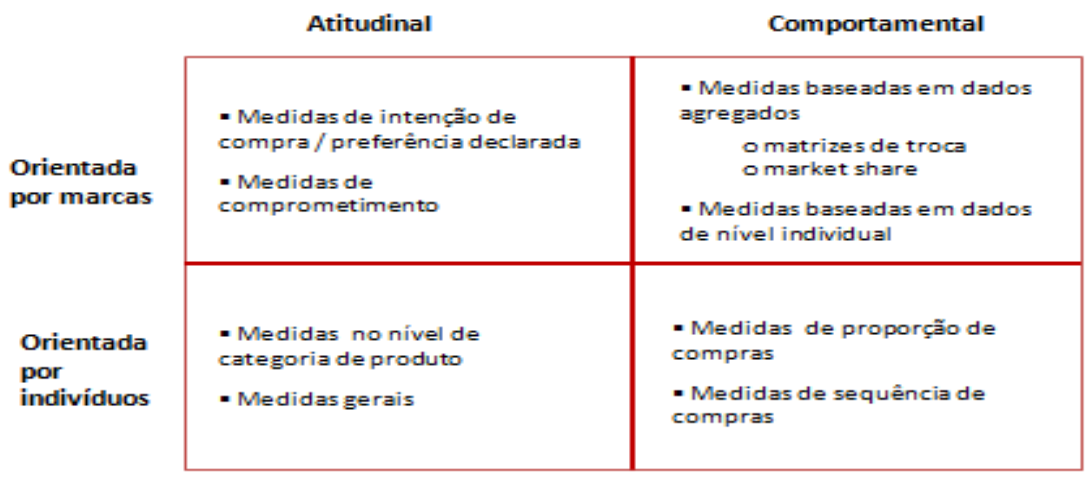

Fonte: Mellens et al. (1996)

\section{Conclusão e Sugestão de Estudos Futuros}

Este artigo apresentou uma revisão teórica sobre lealdade do consumidor às marcas. A justificativa para o tema partiu da significativa relevância do construto, suportada por estudos que mediram os benefícios que a manutenção de clientes leais trazem às organizações. Em seguida, foram apresentadas as principais 
definições conceituais de lealdade, e o debate sobre as abordagens comportamentais e atitudinais do construto. Essas diferentes perspectivas têm implicações diretas sobre a forma de mensuração de lealdade.

A revisão teórica do presente artigo expõe a complexidade de se trabalhar com o construto lealdade, e os cuidados que o pesquisador deve levar em consideração na hora de operacionalizar e medir o construto. A abordagem puramente comportamental pode levar a conclusões errôneas sobre a verdadeira lealdade do consumidor. Por sua vez, considerar a lealdade como um construto puramente atitudinal pode mascarar os resultados de uma investigação, pois nem sempre as atitudes e intenções se traduzem em comportamentos efetivos. A abordagem composta, considerando-se ambos os comportamentos e atitudes, parece ser, portanto, a mais adequada para operacionalizar a lealdade à marca. Contudo, isso introduz maior complexidade ao delineamento de pesquisa, com a inclusão de um maior número de variáveis a serem consideradas.

Outro aspecto a ser considerado é se podemos continuar falando em lealdade em contextos onde o consumidor apresenta preferência e/ou padrão de repetição na compra de mais de uma marca. Uma situação em que um consumidor compra com frequência apenas duas marcas é bem diferente de quando compra marcas diferentes em cada compra. Não há consenso na literatura sobre essa questão, e o mais recomendável é que o pesquisador defina e operacionalize o construto de forma clara, estabelecendo precisamente um ponto de corte (por exemplo, lealdade à marca A existe se o consumidor a adquire em pelo menos $70 \%$ das vezes).

O pesquisador deve também levar em conta os objetivos de sua pesquisa no delineamento de sua investigação. Se o foco é na lealdade de determinadas marcas dentro de certas categorias, as medidas devem ser orientadas por marcas (por exemplo "adquiro sempre a marca A, quando compro sabão em pó”). Nesse caso, as diferenças entre indivíduos são menos importantes, e os dados são agregados por marca. Contudo, o pesquisador pode estar interessado em diferenças de lealdade entre indivíduos, como, por exemplo, grupos culturalmente distintos, ou diferenças de ciclo de vida, renda, pesonalidade etc. Nesse caso, a marca em si é menos relevante.

Embora longe de ser uma revisão exaustiva, foi possível observar uma relativa escassez de estudos que investigassem o efeito de importantes variáveis demográficas no processo de lealdade às marcas. Por exemplo, a ascenção das classes socioeconômicas mais baixas em países emergentes aumenta a relevância sobre o tema da lealdade às marcas entre diferentes estratos. Dado o enfoque das pesquisas acadêmicas internacionais em amostras de consumidores de maior nível de renda em países desenvolvidos (HAMILTON; CATERALL, 2005; GBADAMOSI, 2009), seria interessante observar diferenças quanto à lealdade em diferentes estratos socioeconômicos para diferentes categorias de produtos (ex. hedônicos vs. funcionais). Outro tema que merece atenção para estudos futuros de lealdade são produtos e serviços ligados ao consumerismo ético ou os chamados produtos verdes. Apesar de o marketing verde ter recebido considerável atenção durante a última década devido à maior consciência ambiental do público em geral (MOSTAFA, 2007; LIN; LOBO; LECKIE, 2017), pouca ênfase tem sido dada aos comportamentos e atitudes de lealdade à marca relacionados ao marketing verde (MARTINEZ, 2015; PAPISTA; CHRYSOCHOU; KRYSTALLIS; DIMITRIADIS, 2018; LIN; LOBO; LECKIE, 2019).

\section{Referências}

AMINE, Abdelmajid. Consumer's true brand loyalty: The central role of commitment. Journal of Strategic Marketing. v.6, n.4, p. 305-319, 1998.

AGRAWAL, Richa; GAUR, Sanjaya; NARAYANAN, Archana. Determining customer loyalty: review and model. The Marketing Review, v. 12, n. 3, p. 275-289, 2012.

ANDERSON, Rolph; SRINIVASAN, Srini. E-satisfaction and e-loyalty: A contingency framework. Psychology and Marketing. v.20, n.2, p. 123-138, 2003.

BAGOZZI, Richard; ROSA, Jose Antonio; CELBY, Kirti; CORONEL, Francisco. Marketing Management. New Jersey: Prentice Hall, 1998 
BALDINGER, Allan; RUBINSON, Joel. Brand loyalty: the link between attitude and behavior. Journal of Advertising Research, v. 36, n. 6, p. 22-35, 1996.

BARNARD, Neil; EHRENBERG, Andrew. Advertising: strongly persuasive or nudging. Journal of Advertising Research, v. 37, n.1, p. 21-31, 1997.

BASS, Frank. The theory of stochastic preference and brand switching. Journal of Marketing Research, v. 11, n. 1, p. 1-20, 1974.

BENDER, Paul. The relationships of customer satisfaction, customer loyalty, and profitability. An empirical study. International Journal of Service Industry Management. v.7, n.4, 1976.

BENNETT, Rebekah; BOVE, Liliana. Identifying the key issues for measuring loyalty. Australasian Journal of Market Research, v. 9, n. 2, p. 27-44, 2002.

BENNET, Rebekah; RUNDLE-THIELE, Sharyn. A comparison of attitudinal loyalty measurement approaches. Journal of Brand Management, v.9, n.3, 2002.

BLOEMER, Josée; KASPER, Hans. The complex relationship between customer satisfaction and brand loyalty. Journal of Economic Psychology. v.16, n.2, 1995.

BREI, Vinícius; VIEIRA, Valter; MATOS, Celso. Meta-Análise em marketing. REMark - Revista

Brasileira de Marketing, v. 30, n. 2, 2014.

BROWN, George. Brand loyalty: Fact or fiction? Advertising Age. v.23, June 1952.

CENGIZ, Hakan; AKDEMIR-CENGIZ, Hülya. Review of brand loyalty literature: $2001-2015$. Journal of Research in Marketing, v. 6, n. 1, p.407-432, 2016.

CHAUDHURI, Arjun. Brand equity or double jeopardy? Journal of Product \& Brand Management, v. 4, n. 1, 1995.

CHAUDHURI, Arjun; HOLBROOK, Morris. The chain of effects from brand trust and brand affect to brand performance: The role of brand loyalty. Journal of Marketing, v. 65, n. 2, p. 81-93, 2001.

COPELAND, Melvin. Relation of consumer's buying habits to marketing methods. Harvard Business Review. v.1, n.3, p. 282-289, 1923.

COUTINHO, Marco Antonio; MESQUITA, José Marcos; MUYLDER, Cristiana. Ultimate loyalty: A case study of Harley-Davidson clients. Revista Pensamento Contemporâneo em Administração, v. 12, n. 3, p.143-154, 2018.

CUNNINGHAM, Ross. Brand loyalty: Where, what, and how much? Harvard Business Review. v.24, 1956.

DAY, George. A two-dimensional concept of brand loyalty. Journal of Advertising Research. v.9, n.5, p. 29-35, 1969.

DAY, George; SHOCKER, Allan; SRIVASTAVA, Rajendra. Customer-oriented approaches to identifying product-markets. Journal of Marketing. v.43, n.4, p. 8-19, 1979.

DEKIMPE, Marnik; STEENKAMP, Jan-Benedict; MELLENS, Martin; ABEELE, Piet. Decline and variability in brand loyalty. International Journal of Research in Marketing, v. 14, n. 5, p.405-420, 1997.

BALLESTER, María Elena Delgado. Estado actual de la investigación sobre la lealtad a la marca: una revisión teórica. Dirección y Organización, n. 30, 2004.

DICK, Alan; BASU, Kunal. Customer loyalty: Toward an integrated conceptual framework. Journal of the Academy of Marketing Science, v. 22, n. 2, p. 99-113, 1994.

GBADAMOSI, Ayantunji. Low-income consumers' reactions to low-involvement products. Marketing Intelligence \& Planning, v. 27, n. 7, p. 882-899, 2009.

HA, Choong. The theory of reasoned action applied to brand loyalty. Journal of Product and Brand Management, v. 7, n. 1, p.51-61, 1998. 
HAMILTON, Kathy L.; CATTERALL, Miriam. Towards a better understanding of the low-income consumer. Advances in Consumer Research, v. 32, n. 1, p. 627-632, 2005.

HAUSER, John R.; TOUBIA, Olivier; EVGENIOU, Theodoros; BEFURT, Rene; Dzyabura, Daria. Disjunctions of conjunctions, cognitive simplicity, and consideration sets. Journal of Marketing Research, v. 47, n. 3, p. 485-496, 2010.

HOMBURG, Christian; GIERING, Annette. Personal characteristics as moderators of the relationship between customer satisfaction and loyalty - an empirical analysis. Psychology \& Marketing, v.18, n.1, p. 43-66, 2001.

JACOBY, Jacob; KYNER, David. Brand loyalty vs. repeat purchasing behavior. Journal of Marketing Research. v.10, n.1, p. 1-9, 1973.

JACOBY, Jacob; CHESTNUT, Robert. Brand Loyalty: Measurement and Management. John Wiley and Sons, 1978.

KABIRAJ, Sajal; SHANMUGAN, Joghee. Development of a conceptual framework for brand loyalty: A euro-mediterranean perspective. Journal of Brand Management, v. 18, n. 4-5, p. 285-299, 2011.

KNOX, Simon; WALKER, David. Empirical developments in the measurement of involvement, brand loyalty and their relationship in grocery markets. Journal of Strategic Marketing, v.11, n. 4, p. 271-286, 2003.

LIN, Jialing; LOBO, Antonio; LECKIE, Civilai. Green brand benefits and their influence on brand loyalty. Marketing Intelligence \& Planning, v. 35, n. 3, p. 425-440, 2017.

LIN, Jialing; LOBO, Antonio; LECKIE, Civilai. The influence of green brand innovativeness and value perception on brand loyalty: the moderating role of green knowledge. Journal of Strategic Marketing, $v$. 27, n. 1, p. 81-95, 2019.

MARTÍNEZ, Patricia. Customer loyalty: exploring its antecedents from a green marketing perspective. International Journal of Contemporary Hospitality Management, v. 27, n. 5, p. 896-917, 2015.

MELLENS, Martin; DEKIMPE, Marnik; STEENKAMP, Jan-Benedict A review of brand loyalty measures in marketing. Tijdschrift voon Economic en Management, v.41, n.4, 1996.

MOSTAFA, Mohamed M. A hierarchical analysis of the green consciousness of the Egyptian consumer. Psychology \& Marketing, v. 24, n. 5, p. 445-473, 2007.

NEDUNGADI, Prakash. Recall and consumer consideration sets: Influencing choice without altering brand evaluations. Journal of Consumer Research, v. 17, n. 3, p. 263-276, 1990.

OLIVER, Richard. Whence consumer loyalty. Journal of Marketing. v.63, n.4, p. 33-44, 1999.

OLSHAVSKY, Richard; GRANBOIS, Donald. Consumer decision making-fact or fiction? Journal of Consumer Research, v. 6, n. 2, p. 93-100, 1979.

OSTLUND, Lyman. Evoked set size: some empirical results. Combined Proceedings, editor Thomas V. Greer, Chicago: American Marketing Association, p. 226-30, 1973.

PAN, Yue; SHENG, Simon; XIE, Frank. Antecedents of customer loyalty: An empirical synthesis and reexamination. Journal of Retailing and Consumer Services, v. 19, n. 1, p. 150-158, 2012.

PAPISTA, Erifili; CHRYSOCHOU, Polymeros; KRYSTALLIS, Athanasios; DIMITRIADIS, Sergios. Types of value and cost in consumer-green brands relationship and loyalty behaviour. Journal of Consumer Behaviour, v. 17, n. 1, p. e101-e113, 2018.

PETER, J. Paul; OLSON, Jerry. Comportamento do consumidor e estratégia de marketing. $8^{\mathrm{a}}$ Ed., São Paulo: McGraw Hill, 2009.

PRITCHARD, Mark; HAVITZ, Mark; HOWARD, Denis. Analyzing the commitment-loyalty link in customer contexts. Journal of The Academy of Marketing Science. v.27, n.3, p. 333-348, 1999. 
PRITCHARD, Mark; HOWARD, Denis; HAVITZ, Mark. Loyalty measurement: A critical examination and theoretical extension. Leisure Sciences, v.14, n.2, p. 155-164, 1992.

QUESTER, Pascale; LIM, Ai. Product involvement/brand loyalty: Is there a link? Journal of Product \& Brand Management, v. 12, n. 1, p. 22-38, 2003.

RAUYRUEN, Prapassapa; MILLER, Kenneth. Relationship quality as a predictor of B2B customer loyalty and profits. Journal of Business Research, v.60, n.1, 2007.

REICHHELD, Frederic; SASSER, W. Earl. Zero defections: Quality comes to services. Harvard Business Review, v.68, n.5, p. 105-111, Sep-Oct, 1990.

REILLY, Michael; PARKINSON, Thomas L. Individual and product correlates of evoked set size for consumer package goods. Advances in Consumer Research. v.12, p.492-497, 1985.

ROCHA, Viviane; PONCHIO, Mateus; FRANCISCO, Eduardo. Lealdade do consumidor e programas de fidelidade: Uma análise topográfica do campo de conhecimento à luz da bibliometria, da estatística espacial e das redes sociais. Revista de Ciências da Administração, v.17, n.41, p. 9-20, 2014.

ROTHSCHILD, Michael; GAIDIS, William. Behavioural learning theory: Its relevance to marketing and promotions, Journal of Marketing, v. 45, n. 2, p.70-781, 1981.

ROWLEY, J.; DAWES, J. Disloyalty: a closer look at non-loyals. Journal of Consumer Marketing, v.17 n.6, pp.538 - 547, 2000.

RUNDLE-THIELE, Sharyn; BENNETT, Rebekah. A brand for all seasons? A discussion of brand loyalty approaches and their applicability for different markets. Journal of Product and Brand Management, v. 10, n. 1, p.25-37, 2001.

SHETH, Jagdish N. Measurement of multidimensional brand loyalty of a consumer. Journal of Marketing Research. v.7, n.3, p.348-354, 1970.

SHETH; Jagdish; KOSCHMANN, Anthony. Do brands compete or coexist? How persistence of brand loyalty segments the market? European Journal of Marketing, v. 53 n. 1, p.2-19, 2019

SPLITTER, Karla; ROSA, Carolina; BORBA, José Alonso. Uma análise das características dos trabalhos "ditos" bibliométricos publicados no Enanpad entre 2000 e 2011. In: Encontro da ANPAD, 36., 2012, Rio de Janeiro. Anais... Rio de Janeiro: ANPAD. 2012.

TERECH, Andres; BUCKLIN, Randolph; MORRISON Donald. Consideration, choice, and classifying loyalty. Marketing Letters, v. 20, n. 3, 2009.

TUCKER, William. The development of brand loyalty. Journal of Marketing Research. v.1, n.3, 1964.

UNCLES, Mark; WANG, Chao; KWOK, Simon. A temporal analysis of behavioural brand loyalty among urban Chinese consumers. Journal of Marketing Management, v.26, n.9-10, p.921-942, 2010.

VAN NIEROP, Erjen; BRONNENBERG, Bart; PAAP, Richard; WEDEL, Michel; FRANSES, Philip. Retrieving unobserved consideration sets from household panel data. Journal of Marketing Research, v. 47, n. 1, p. 63-74, 2010.

VIEIRA, Valter. Efeitos curvilineares da lealdade no comportamento do consumidor. RAM. Revista de Administração Mackenzie, v. 13, n. 2, p. 227-253, 2012.

VISENTINI, Monize; FENNER, Vanessa. Lealdade: Análise da produção científica brasileira aa área de marketing no período compreendido entre 2010 e 2016. Perspectivas em Gestão e Conhecimento, v. 7, n. 2, p. 175-198, 2017.

WORTHINGTON, Steve; RUSSEL-BENNETT, Rebekah; HÄRTEL, Charmine. A tri-dimensional approach for auditing brand loyalty. Journal of Brand Management, v. 17, n. 4, p. 243-253, 2010.

YOO, Myongjee; BAI, Billie. Customer loyalty marketing research: A comparative approach between 
hospitality and business journals. International Journal of Hospitality Management, v. 33, p. 166-177, 2013.

ZINS, Andreas. Relative attitudes and commitment in customer loyalty models. Some experiences in the commercial airline industry. International Journal of Service Industry Management, v. 23, n.3\&4, p. 269-294, 2001.

Submetido em: 19/06/2019

Aceito em: 02/09/2019 